\title{
INCIDÊNCIA E SEVERIDADE DO VÍRUS DO ENDURECIMENTO DOS FRUTOS EM MARACUJAZEIROS ENXERTADOS EM PÉ-FRANCO ${ }^{1}$
}

\author{
JOSÉ CARLOS CAVICHIOLI ${ }^{2}$, LUIZ DE SOUZA CORRÊA ${ }^{3}$, NOBUYOSHI NARITA ${ }^{4}$, \\ FRANCISCO SEIITI KASAI ${ }^{5}$
}

RESUMO - O objetivo deste trabalho foi avaliar a incidência e a severidade do vírus do endurecimento dos frutos em maracujazeiro-amarelo enxertado e pé-franco. O experimento foi conduzido no município de Adamantina-SP, no período de abril de 2006 a junho de 2007, adotando-se o delineamento em blocos ao acaso, com quatro tratamentos e oito repetições. Foram avaliados três porta-enxertos: Passiflora edulis, P. alata e P. gibertii, e plantas de pé-franco. Utilizou-se como copa o maracujazeiro-amarelo (Passiflora edulis Sims). Avaliaram-se a porcentagem de plantas com sintomas de virose e a severidade dos sintomas. As primeiras plantas com sintomas de virose ocorreram aos 90 dias do plantio das mudas no campo, atingindo, aos 180 dias, $100 \%$ de plantas com virose em P. alata e P. gibertii, e 97,5\% em P. edulis e pé-franco.

Termos para indexação: maracujá-amarelo, Passifloraceae, virose.

\section{OCURRENCE AND SEVERITY OF MOSAIC VÍRUS ON PASSION FRUIT}

\begin{abstract}
The aim of this work was to evaluate the percentage of plants with symptoms of Cowpea aphid-borne mosaic virus (CABMV) and the severity of the symptoms, in yellow passionfruit (Passiflora edulis Sims) grafted and not grafted. The experiment was carried out in Adamantina, SP, Brazil, from April 2006 to June 2007, adopting the experimental design in randomized blocks with four treatments and eight replicates. The studied factors were three rootstocks: Passiflora edulis, $P$. alata and $P$. gibertii, and plants not grafted. It was used the yellow passion fruit (Passiflora edulis Sims) as graft. The variables evaluated were: percentage of plants with symptoms of CABMV and the severity of the symptoms. The first plants with symptoms of CABMV occurred 90 days after planting in the field, reaching 180 days after planting $100 \%$ of plants with CABMV in P. alata and P. gibertii and $97,5 \%$ in P. edulis and in not grafted plants.
\end{abstract}

Index terms: yellow passion fruit, Passifloraceae, viruses.

\section{INTRODUÇÃO}

A cultura do maracujazeiro pode ser infectada por diversas viroses, porém o vírus do endurecimento dos frutos é o que predomina e o que causa os maiores prejuízos (YUKI et al., 2006a). É causada principalmente pelo Cowpea aphid-borne mosaic vírus (CABMV), doença de etiologia viral mais importante no Brasil e que está disseminada na maioria das regiões produtoras (NACIMENTO et al., 2006). Em virtude da alta incidência, a cultura vem tornando-se anual, pois, antes de ocorrerem as epidemias, a cultura era perene e cultivada pelo menos três anos consecutivos (YUKI et al., 2006a).
Esse vírus causou praticamente o desaparecimento da cultura na região de Marília e vem reduzindo drasticamente a cultura no Vale do Ribeira (YUKI et al., 2006b).

Os sintomas do CABMV caracterizam-se pela presença de mosaico comum, acompanhados em alguns casos de enrugamento e distorção foliar (REZENDE, 2006). Plantas infectadas têm sua produção reduzida quantitativa e qualitativamente, já que os frutos ficam menores, deformados e endurecidos (GIORIA et al., 2000).

Frutos colhidos de plantas com virose podem não atender às expectativas dos diferentes segmentos consumidores, nas suas características

\footnotetext{
${ }^{1}$ Trabalho Sinfruit 012 - Simpósio Internacional de Fruticultura - Avanços na Fruticultura (17 a 21 Outubro)

${ }^{2}$ Pesquisador da APTA Regional Alta Paulista, Caixa Postal 191, 17.800-000, Adamantina (SP), fone: (18) 3521-4800.

E-mail: jccavichioli@apta.sp.gov.br

${ }^{3}$ Professor Titular do Depto. Fitotecnia, Tecnologia de Alimentos e Socioeconomia da FEIS-UNESP. E-mail: 1correa@agr.feis.unesp.br ${ }^{4}$ Pesquisador da APTA Regional Alta Sorocabana, Caixa Postal 298, 19.015-970, Presidente Prudente (SP), fone: (18) 3222-0732. E-mail: narita@apta.sp.gov.br

5Pesquisador da APTA Regional Alta Paulista, Caixa Postal 191, 17.800-000, Adamantina (SP), fone: (18) 3521-4800.

E-mail: fskasai@apta.sp.gov.br
} 
internas e externas. De acordo com Balbino (2005), as características internas dos frutos estão relacionadas ao sabor (teor de acúcares e acidez) e conteúdo de suco (rendimento), enquanto as características externas devem atender a padrões para que atinjam a qualidade desejada na comercialização (NASCIMENTO et al., 1999).

O uso da enxertia no maracujazeiro é uma técnica que já foi descrita por diversos autores (CHAVES et al., 2004; SILVA et al., 2005; CAVICHIOLI et al., 2009) e pode ser uma forma de resolver problemas com algumas doenças na cultura (JUNQUEIRA et al., 2006).

Considerando que a aparência é o critério mais utilizado pelos consumidores para avaliar a qualidade dos frutos de maracujazeiro (ABREU et al., 2009) e que a virose provoca sérios danos aos mesmos, o presente o estudo teve por objetivo avaliar a produção e a qualidade de frutos de maracujazeiroamarelo obtidos de plantas de pé-franco e de plantas enxertadas em área com ocorrência do vírus do endurecimento dos frutos.

\section{MATERIAL E MÉTODOS}

O experimento foi conduzido no município de Adamantina, na região da Nova Alta Paulista, em uma propriedade localizada a $397 \mathrm{~m}$ de altitude, $21^{\circ} 42^{\prime} \mathrm{S}$ de latitude e $51^{\circ} 09^{\prime} \mathrm{W}$ de longitude, no período de abril de 2006 a junho de 2007, em área com ocorrência de vírus do endurecimento dos frutos. O solo da área experimental foi classificado como Argissolo Vermelho-Amarelo, eutrófico, A moderado, textura arenosa/média e topografia ondulada.

O clima da região é Cwa, segundo a classificação de Köeppen, com estação chuvosa no verão e estação seca no inverno. A precipitação média anual é de $1.300 \mathrm{~mm}$. A temperatura média anual está em torno de $22-23^{\circ} \mathrm{C}$.

Adotou-se o delineamento estatístico em blocos ao acaso, com quatro tratamentos e oito repetições, e cinco plantas por parcela. Os fatores avaliados foram três porta-enxertos: Passiflora edulis (maracujá-amarelo), P. alata (maracujá-doce) e $P$. gibertii (maracujá-giberti) e um tratamentotestemunha (sem enxertia).

O espaçamento da cultura foi de 5,0 metros entre plantas por 3,2 metros entre ruas. A área de cada parcela foi de $80 \mathrm{~m}^{2}$. O plantio das mudas foi realizado no dia 13 de abril de 2006 e foram conduzidas com um único ramo vegetativo (ramo primário) até atingir o segundo fio de arame, sendo que as brotações laterais foram eliminadas.
Foram avaliadas as seguintes características: a) Porcentagem de plantas com sintomas de virose: foi realizada mensalmente a contagem de plantas que apresentavam sintomas do vírus do endurecimento dos frutos.

b) Severidade dos sintomas: foi feito seguindo a Metodologia de Abreu et al. (2008), que atribui um sistema de notas de acordo com a sintomatologia visual das folhas, assim descrita: nota 1 , folhas sem sintomas de mosaico; nota 2, folhas apresentando mosaico leve e sem deformações foliares; nota 3 , folhas apresentando mosaico leve, bolhas e deformações foliares, e nota 4 , folhas apresentando mosaico severo, bolhas e deformações foliares.

\section{RESULTADOS E DISCUSSÃO}

Os primeiros sintomas do vírus do endurecimento dos frutos em plantas de maracujazeiroamarelo foram observados aos 90 dias do plantio das mudas no campo, atingindo 5\% das plantas de pé-franco e das enxertadas sobre $P$. edulis, $7,5 \%$ das plantas enxertadas sobre $P$. alata e $12,5 \%$ das plantas enxertadas sobre $P$. gibertii (Figura 1).

Houve efeito significativo entre as épocas de avaliação quanto à porcentagem de plantas afetadas. O maior aumento na incidência da doença ocorreu dos 90 aos 120 dias do plantio, período em que todos os tratamentos apresentaram aumentos significativos na incidência da virose, atingindo $52,5 \%$ das plantas enxertadas sobre $P$. alata, seguida de P. edulis, com 51,25\%, P. gibertii, com 45,6\% e de plantas de pé-franco com $45 \%$ (Figura 1). Também ocorreu aumento significativo nos três tratamentos no período dos 120 aos 150 dias, chegando a atingir $90 \%$ das plantas de pé-franco. Aos 180 dias do plantio no campo, $100 \%$ das plantas de pé-franco e das enxertadas sobre $P$. alata já estavam infectadas com o CABMV, enquanto em $P$. gibertii e em $P$. edulis esse índice era de $97,5 \%$ de plantas infectadas. Esse resultado concorda com Yuki et al. (2006b), quando observaram que o vírus pode afetar toda a cultura em menos de 5 meses do plantio. Não houve diferenças entre os porta-enxertos nas avaliações realizadas aos 90; $120 ; 150$ e 180 dias.

Com relação à severidade dos sintomas do CABMV, observou-se que, aos 90 dias, não houve diferenças estatísticas entre os tratamentos, variando de 1,05 em plantas de pé-franco a 1,2 em plantas enxertadas sobre $P$. gibertii (Figura 2), manifestandose na forma de mosaico leve e sem deformações foliares. Observou-se que, com o desenvolvimento das plantas e com o aumento da incidência da virose (Figura 1), houve maior severidade dos sintomas, 
atingindo, aos 120 dias do plantio, médias que variaram de 1,6 no pé-franco a 1,8 em P. alata; porém, sem apresentar diferenças significativas entre os porta-enxertos.

Na comparação entre as épocas de avaliação, nota-se que, dos 90 aos 120 dias, houve aumento significativo na severidade dos sintomas, com exceção para as plantas enxertadas sobre $P$. gibertii. Dos 120 aos 150 dias, todos os tratamentos apresentaram aumento significativo na severidade dos sintomas da virose (Figura 2). $\mathrm{O}$ mesmo não ocorreu dos 150 aos 180 dias, quando não foi verificado diferença para nenhum dos tratamentos. Finalmente, dos 180 aos 330 dias, novamente todos os tratamentos tiveram aumento significativo na severidade dos sintomas, sendo maiores nas plantas enxertadas sobre $P$. gibertii, com 3,8, diferindo de $P$. alata e de plantas de pé-franco. Nesta fase, a maioria das plantas apresentava folhas com mosaico severo, bolhas e deformações e frutos pequenos, deformados e com pericarpo endurecido. Nogueira Filho et al. (2010), estudando o desenvolvimento de plantas de maracujazeiro-amarelo sobre seis porta-enxertos verificaram menor vigor do $P$. gibertii em relação à plantas de pé-franco e plantas enxertadas sobre $P$. edulis, o que pode explicar a maior severidade dos sintomas de virose observada em plantas enxertadas sobre este porta-enxerto.

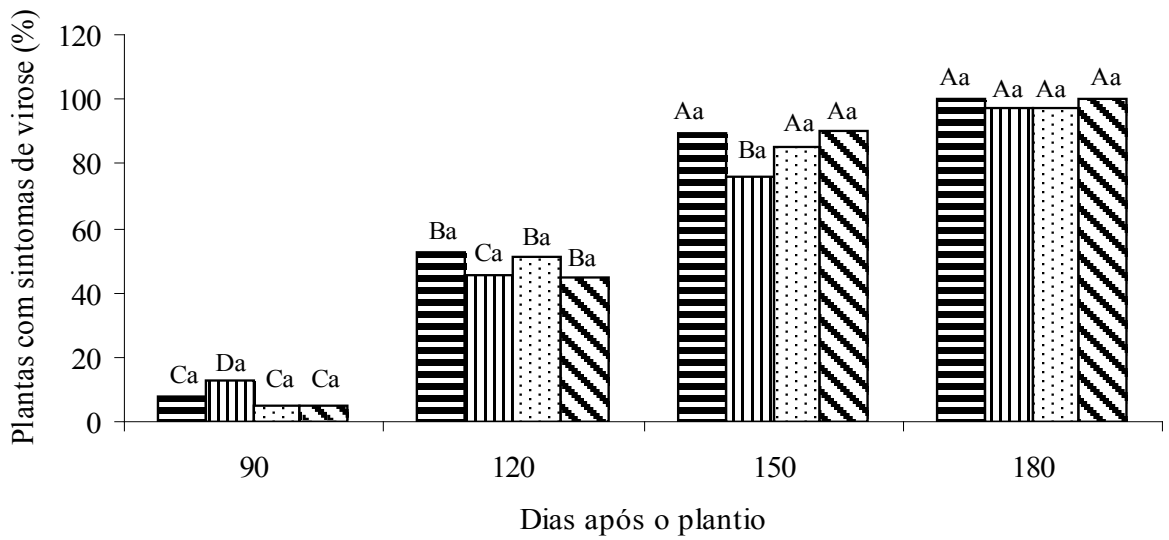

$\Xi$ P. alata $\square$ P. gibertii $\square$ P. edulis $\mathbf{m}$ Pé-franco

FIGURA 1 - Incidência de virose (\%) em plantas de maracujazeiro-amarelo enxertadas e pé-franco, aos 90; 120; 150 e 180 dias após o plantio no campo. Adamantina-SP, 2006/2007.

Médias seguidas da mesma letra minúscula dentro de "Dias após o plantio" e médias seguidas da mesma letra maiúscula dentro do porta-enxerto, não diferem significativamente, pelo teste de Tukey, a $5 \%$ de probabilidade.

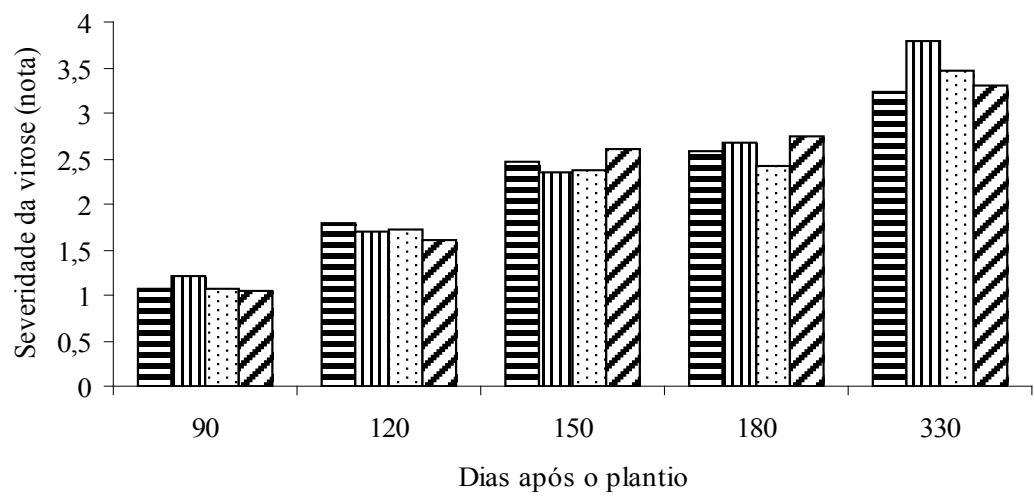

ロP. alata $\square$ P. gibertii $\square$ P. edulis $\square$ Pé-franco

FIGURA 2 - Severidade dos sintomas da virose (nota) em plantas de maracujazeiro-amarelo enxertadas e de pé-franco, aos 90; 120; 150; 180 e 330 dias após o plantio no campo. Adamantina-SP, 2006/2007.

Médias seguidas da mesma letra minúscula dentro de "Dias após o plantio"e médias seguidas da mesma letra maiúscula dentro do porta-enxerto não diferem significativamente, pelo teste de Tukey, a 5\% de probabilidade. 


\section{CONCLUSÕES}

1. O uso de plantas enxertadas não reduz a incidência nem a severidade do vírus do endurecimento dos frutos em maracujazeiro-amarelo.

2. Quanto maior a taxa de incidência de plantas com sintomas do CABMV, maior é a sua severidade.

\section{REFERÊNCIAS}

ABREU, S. de P.M.; PEIXOTO, J.R.; JUNQUEIRA, N.T.V.; SOUSA, M.A. de F. Características físicoquímicas de cinco genótipos de maracujazeiro-azedo cultivados no Distrito Federal. Revista Brasileira de Fruticultura, Jaboticabal, v.31, n.2, p.487-491, 2009.

ABREU, S. de P.M.; PEIXOTO, J.R.; JUNQUEIRA, N.T.V.; SOUSA, M.A. de F. Incidência e severidade da virose do endurecimento em genótipos de maracujazeiro-azedo cultivados no Distrito Federal. In: CONGRESSO BRASILEIRO DE FRUTICULTURA, 20., 2008, Vitória. Anais... Vitória: Sociedade Brasileira de Fruticultura, 2008. CD-ROM.

BALBINO, J.M. de S. Manejo na colheita e póscolheita do maracujá. In: COSTA, A. de F.S.; COSTA, A.N. (Ed.). Tecnologias para a produção de maracujá. Vitória: INCAPER, 2005. p. 153-179.

CAVICHIOLI, J.C.; CORRÊA, L. de S.; BOLIANI, A.C.; OLIVEIRA, J.C. de. Uso de câmara úmida em enxertia hipocotiledonar de maracujazeiro-amarelo sobre três porta-enxertos. Revista Brasileira de Fruticultura, Jaboticabal, v.31, n.2, p.532-538, 2009.

CHAVES, R.C.; JUNQUEIRA, N.T.V.; MANICA, I.; PEIXOTO, J.R.; PEREIRA, A.V.; FIALHO, J.F. Enxertia de maracujazeiro-azedo em estacas herbáceas enraizadas de espécies de passifloras nativas. Revista Brasileira de Fruticultura, Jaboticabal, v.26, n.1, p.120-123, 2004.

GIORIA, R.; BOSQUÊ, G.G.; REZENDE, J.A.M.; AMORIM, L.; KITAJIMA, E.W. Incidência de viroses de maracujazeiro na Alta Paulista - SP, e danos causados pelo "Passion fruit woodiness vírus". Fitopatologia Brasileira, Brasília, v.25, p.182-189, 2000.

JUNQUEIRA, N.T.V.; LAGE, D.A. da C.; BRAGA, M.F.; PEIXOTO, J.R.; BORGES, T.A.; ANDRADE, S.R.M. de. Reação a doenças e produtividade de um clone de maracujazeiro-azedo propagado por estaquia e enxertia em estacas herbáceas de Passiflora silvestre. Revista Brasileira de Fruticultura, Jaboticabal, v.28, n.1, p.97-100, 2006.
NASCIMENTO, T.B. do; RAMOS, J.D.; MENEZES, J.B. Características físicas do maracujá-amarelo produzido em diferentes épocas. Pesquisa Agropecuária Brasileira, Brasília, v.34, n.12, p.2353-2358, 1999.

NASCIMENTO, A.V.S.; SANTANA, E.N.; BRAZ, A.S.K.; ALFENAS, P.F.; PIO-RIBEIRO, G.; ANDRADE, G.P.; CARVALHO, M.G.; ZERBINI, F.M. Cowpea aphid-borne mosaic vírus (CABMV) is widespread in passion fruit in Brazil and causes passionfruit woodiness disease. Archives of Virology, New York, v.151, p. 1797-1809, 2006.

NOGUEIRA FILHO, G.C.; RONCATTO, G.; RUGGIERO, C.; OLIVEIRA, J.C. de; MALHEIROS, E.B. Desenvolvimento e produção das plantas de maracujazeiro-amarelo produzidas por enxertia hipocotiledonar sobre seis porta-enxertos. Revista Brasileira de Fruticultura, Jaboticabal, v.32, n.2, p.535-543, 2010 .

REZENDE, J.A.M. Práticas culturais para prevenção e convivência com as viroses do maracujazeiro. In: SAMPAIO, A.C.; FUMIS, T.F.; ROSSI, A.D.; ALMEIDA, A.M.; GARCIA, M.J.M. (Ed.). Manejo no controle do vírus do endurecimento dos frutos (PWV) do maracujazeiro. Jaboticabal: Multipress, 2006. p.47-58.

SILVA, F.M.; CORRÊA, L.de S.; BOLIANI, A.C.; SANTOS, P.C. dos. Enxertia de mesa de Passiflora edulis Sims f. flavicarpa Deg. sobre Passiflora alata Curtis, em ambiente de nebulização intermitente. Revista Brasileira de Fruticultura, Jaboticabal, v.27, n.1, p.98-101, 2005.

YUKI, V.A.; MIZOTE, F.A.; NARITA, N.; HOJO, H.; DELFINO, M.A.; OLIVEIRA, D.A. Epidemiologia do vírus do endurecimento dos frutos do maracujazeiro na região produtora da Alta Paulista-SP. Summa Phytopathologica, Botucatu, v.32, p. 19, 2006 a. Suplemento.

YUKI, V.A.; FERNANDES, M.S.; SANNAZZARO, A.M.; CAVICHIOLI, J.C.; REZENDE, J.A.M.; KUNIYUKI, H. Efeito do isolamento da cultura de maracujá na epidemiologia do vírus do endurecimento dos frutos. Summa Phytopathologica, Botucatu, v.32, p. 9-98, 2006b. Suplemento. 